\title{
Argentina e Italia ante la diversidad cultural: valoración en sede penal del factor culturalmente relevante
}

\section{POR MARIO CATERINI(*) Y MARIO EDUARDO MALDONADO SMITH(**)}

Sumario: I. Introducción.- II. El caso argentino.- III El caso italiano.IV. Consideraciones y reflexiones. - V. Bibliografía.

Resumen: el presente trabajo estudia la relevancia del factor cultural al interior de las categorías tradicionales de estudio de la dogmática penal, tanto en el ordenamiento jurídico argentino como en el italiano, con el objetivo de determinar en qué medida y bajo qué alcance dicho factor es tomado en consideración. Se analizan particularmente diversos casos tomados de la jurisprudencia de ambos países, incluyendo casos "difíciles" que involucran colisión de derechos fundamentales. Se busca encontrar puntos de conexión, así como herramientas que puedan ser valoradas en los respectivos contextos de análisis.

Palabas claves: cultura - delito culturalmente orientado - multiculturalismo derechos fundamentales

\section{Argentina and Italy in the face of cultural diversity. Criminal valuation of the culturally relevant factor}

Abstract: the present work studies the relevance of the cultural factor within the traditional categories of study of criminal dogmatics, in the Argentine and Italian legal systems, with the aim of determining to what extent and under which this factor reaches is taken into consideration. Various cases taken from the jurisprudence of both countries are particularly analyzed, including "difficult" cases that involve collision of fundamental rights, seeking to find points of connection, as well as tools that can be valued in the respective contexts of analysis.

Keywords: culture - culturally oriented crime - multiculturalism - fundamental rights

$\left(^{*}\right)$ Prof. de Derecho Penal, Universidad de Calabria, Italia. Dir. del Instituto de Estudios Penales "Alimena", Centro de Investigación Interdepartamental: www.unical.it/dices/ispa

(**) Prof. de Derecho Penal Económico, Universidad Internacional de la Rioja. 


\section{Introducción}

Todos los países del mundo son multiculturales, ya lo sean por la presencia en su interior de minorías étnicas, lingüísticas o religiosas autóctonas o bien, como resultado de los diversos procesos migratorios. Cada una de tales colectividades dispone de reglas de conducta que determinan los diversos aspectos de su vida mediante directrices que prefijan los comportamientos esperados ya sea facultándolos, prohibiéndolos o, incluso, disponiendo su obligatoriedad.

Como una consecuencia natural de la amplia diversidad humana, tales reglas de conducta no son iguales en los grupos; sin embargo, en la amplia mayoría de casos existe una cierta coincidencia respecto de los comportamientos esperados. Solo en algunos casos excepcionales que, resaltamos, corresponden más bien a la excepción en las culturas, la divergencia es absoluta y coloca en una situación de gran tensión los presupuestos mínimos para la convivencia pacífica, precisamente es en estos casos cuando el derecho penal es llamado a intervenir como "territorio de frontera" (Basile, 2007, p. 71; Caterini, 2020, p. 118).

Cuando los conflictos anteriores son derivados de pautas de conducta presentes en grupos culturales insertos al interior de un colectivo mayor (digamos, la sociedad general) nos referimos a lo que en la literatura suele conocerse como "delitos culturalmente motivados" (Broeck, 2001, p. 10; Basile, 2008, p. 7). Frente a estos delitos, los ordenamientos jurídicos reaccionan de forma diversa, ya sea a través de una absoluta irrelevancia del factor cultural (modelo de asimilación), mediante una valoración de dicho factor al interior de las categorías tradicionales de la dogmática penal (modelo multicultural tenue) o, incluso, cediendo tal facultad a los propios sujetos interesados mediante el reconocimiento de sus propios sistemas de autoridad y de impartición de justicia, en este último caso, mediante un modelo de fuerte multiculturalidad (De Maglie, 2010, p. 32; Fornasari, 2008, p. 181; Bernardi, 2006, p. 74).

Cada uno de estos modelos responde a exigencias diversas que, del mismo modo, suelen estar condicionadas por factores centrales como lo es el tipo de sociedad multicultural en cuestión, ya sea una de tipo multinacional o de tipo multiétnico (Kymlicka, 1999, p. 15), de igual modo, por divergencias que atraviesan la historia particular de cada Estado y las particulares relaciones que han mantenido con las minorías étnicas, lingüísticas y religiosas existentes en su territorio. Un estudio de tal envergadura, aunque apasionante, sobrepasa tanto las dimensiones como las exigencias que el presente trabajo tiene dispuestas, por lo que, aun reconociendo el necesario estudio de cuestiones preliminares (como las ya adelantadas), así como las diferencias entre los tipos de sociedades multiculturales, no obstante, pretendemos analizar cómo viene valorado el factor cultural en sede penal tanto en la República Argentina como en la italiana. 
De este modo, planteamos que, independientemente del tipo de realidad multicultural, ambos ordenamientos han tomado una posición de frente a la diversidad cultural que ha permitido, en mayor o menor medida, dar relevancia a este componente en sede penal, despejando ya con ello, toda duda respecto de la trascendencia de la multiculturalidad para las sociedades contemporáneas. A la par, veremos cómo ha reaccionado la jurisprudencia de ambos países en casos considerados "difíciles" ante la inevitable colisión de pares derechos fundamentales, intentaremos encontrar puntos de conexión, así como herramientas que puedan ser valoradas en los respectivos contextos de análisis.

\section{El caso argentino}

La República Argentina es un claro ejemplo de un Estado multicultural, y ello tanto por la presencia de minorías étnicas originarias (pueblos indígenas), como por resultado de los diversos procesos migratorios que han acompañado el transcurso de su historia.

En efecto, Argentina se ha caracterizado por ser un país históricamente definido por la inmigración; europea durante los siglos XIX y XX y, contemporáneamente, de países limítrofes, aunque también de regiones tan distantes y diversas como lo podrían ser Siria o Senegal. Igualmente, Argentina alberga a la segunda mayor colectividad judía en el continente americano (solo tras los Estados Unidos), sin contar con la importante presencia de colectivos libaneses, armenios, polacos, japoneses, coreanos, africanos (sobre todo de Cabo Verde), gitanos y menonitas (Restón, 2017, p. 25).

Frente a su abrumadora diversidad cultural, Argentina ha venido reaccionando de un modo progresista que, por lo demás, ha sido coherente con los diversos procesos latinoamericanos de reconocimiento y valoración de las diferencias étnicoculturales, particularmente en sede penal (Vázquez Neira, 2010, p. 12; Valenzuela Reyes, 2003, p. 9). El caso argentino, sin embargo, conjuga de un modo sumamente interesante el fenómeno migratorio con la diversidad étnica de los pueblos indígenas, pues, en un número ampliamente significativo, los inmigrantes son también portadores de la calidad de indígenas o bien, se les equipara bajo la categoría de minorías culturales símiles (como en el caso de los gitanos o incluso los amish).

Tratándose de la población indígena, la cláusula constitucional que la reconoce y tutela corresponde al artículo 75, inciso 17, en el que se dispone como una facultad del Congreso Nacional el "Reconocer la preexistencia étnica y cultural de los pueblos indígenas argentinos". El mismo artículo, además, les reconoce personalidad jurídica y garantiza, entre otras cosas, el respeto a su identidad cultural (Bidart Campos, 1994, p. 371). 
La disposición en comento ha sido incorporada al texto constitucional a partir de la trascendental reforma de 1994. A propósito, y junto con la mayoría de las Constituciones latinoamericanas que en dicho periodo realizaron reformas estructurales, la Argentina también modificó el hasta entonces imperante modelo de asimilación para pasar a asumir uno de tipo multicultural. Sirva como ejemplo la anterior previsión constitucional referida a los pueblos indígenas que, en el artículo 67, inciso 15, disponía, como parte de las atribuciones del Congreso, el "conservar el trato pacífico con los indios y promover la conversión de ellos al catolicismo".

Ahora bien, si se le compara con otras experiencias de la región (Jiménez Fortea, 2007, p. 16), Argentina parece haber optado por un constitucionalismo multicultural de impronta reservada en tanto que, si bien reconoce el derecho y la protección a la identidad cultural, no hace lo propio (en apariencia) con el derecho fundamental a la libre autodeterminación y a los derechos derivados de este, como lo es, el pluralismo jurídico, una situación que, como adelantamos sí se ha realizado en diversas constituciones latinoamericanas (Ramírez, 2006, p. 43; Van Cott, 2000, p. 257).

La situación es solo "aparente", en tanto que la autodeterminación y sus componentes (entre ellos, el pluralismo jurídico) son parte del ordenamiento jurídico argentino por vía de la incorporación del derecho internacional que la propia Constitución Nacional (CN) realiza (artículo 75, inciso 22). A este respecto, corresponde destacar el emblemático Convenio № 169 de la Organización Internacional del Trabajo sobre Pueblos Indígenas y Tribales en países independientes (Caesano, 2009, p. 6) que, como es sabido, constituye la herramienta normativa más importante a nivel internacional en relación con el reconocimiento, protección y defensa de los pueblos indígenas, así como de minorías étnicas equiparables. Entre otros tantos derechos, el Convenio prevé el reconocimiento de los propios sistemas normativos indígenas, con sus respectivas autoridades e instituciones tradicionales, siempre bajo el límite del respeto inquebrantable a los derechos humanos internacionalmente reconocidos (Olguín Ríos, 2018, p. 3). Dicho Convenio ha sido ratificado por la Argentina y, mediante la ley 24071, ha sido incorporado al ordenamiento nacional, por lo que, a todos sus efectos, es completamente obligatorio (Stornelli, 2019, p. 7).

Además, y en términos que no solo conciernen a los pueblos indígenas sino a las diversas minorías étnicas, lingüísticas, religiosas y culturales, importa resaltar que disponen de jerarquía constitucional (artículo 75, inciso $22 \mathrm{CN}$ ): la Declaración Americana de los Derechos y Deberes del Hombre, la Declaración Universal de Derechos Humanos, la Convención sobre los Derechos del Niño y la Convención Americana sobre Derechos Humanos, todas ellas con sendas referencias al 
derecho fundamental a la cultura y a la identidad. En el caso de esta última - la Convención Americana-, cabe también precisar que, en la mayoría de los países americanos, incluida la Argentina, opera un sistema de control de convencionalidad realizado por la Corte Interamericana de Derechos Humanos quien, además de fungir como tribunal americano, también asume la función de intérprete "auténtico" del contenido de la Convención (Stornelli, 2019, p. 8). La Corte, en esta línea argumentativa, dispone ya de una robusta experiencia contenciosa, y de interpretación, en temáticas vinculadas con la identidad cultural, particularmente en temas indígenas.

Mención aparte merecen el Pacto Internacional de Derechos Civiles y Políticos que, además de disponer de un rango constitucional, contiene una referencia explícita al derecho a la identidad cultural de las diversas minorías étnicas, religiosas o lingüísticas (Ramírez, 2007, p. 7). Tal artículo viene acompañado de la interpretación, también auténtica, que del mismo ha realizado el Comité de Derechos Humanos de las Naciones Unidas mediante su Observación General № 23, intitulada "Derecho de las minorías", que proporciona múltiples directrices a aplicar por los Estados parte al momento de garantizar las diversas manifestaciones de la identidad cultural de estos grupos. De este modo, el derecho de fuente internacional, incorporado directamente por la Constitución Nacional, viene a complementar al panorama argentino en lo que hace al reconocimiento de la diversidad cultural.

Siempre en el ámbito nacional es de destacar, igualmente, entre otros avances normativos dirigidos a la revalorización del patrimonio cultural indígena la ley 26.160 relativa a la "Emergencia en materia de posesión y propiedad de tierras". Igualmente, la ley 23.302 sobre "Políticas Indígenas y Apoyo a las Comunidades Aborígenes" y su decreto reglamentario No 155/89, del 17 de febrero de 1989. Asimismo, el Código Civil y Comercial de la Nación, en su artículo 18, prevé un explícito reconocimiento de derechos indígenas referente a la posesión y propiedad comunitaria de sus tierras tradicionales (Benítez, 2016, p. 17).

En términos más amplios dirigidos al reconocimiento de la cultura, la Ley de Migración Argentina (ley 25.871) reconoce el derecho a una inclusión adecuada de los migrantes, junto con el fomento y la promoción de sus expresiones culturales, recreativas, sociales, económicas y religiosas, dirigidas al logro de la "convivencia en una sociedad multicultural" (artículo 14). Asimismo, la Ley sobre la promoción de la diversidad de las expresiones culturales (ley 26.305) incorpora directamente al ordenamiento nacional la Convención UNESCO sobre la protección y promoción de la diversidad de las expresiones culturales, la que dispone un amplio catálogo de medidas dirigidas al respeto y promoción de las diversas identidades y expresiones culturales (Villalba, 2014, p. 160). 
En el ámbito de las políticas públicas se destaca por parte de la Defensoría General de la Nación el Programa sobre Diversidad Cultural destinado precisamente a difundir lo que podríamos catalogar como "buenas prácticas culturales" en el ámbito de la asistencia penal(1). Dicho programa insta a los diversos servidores públicos a asumir una perspectiva cultural en todos aquellos casos en los que puedan verse comprometidos indígenas, extranjeros y cualquier minoría étnica, lingüística y cultural. El programa, bajo la hipótesis de un posible delito culturalmente motivado permite a los operadores jurídicos leer el derecho en clave multicultural para poder, eventualmente, encuadrar una determinada conducta bajo la hipótesis de una causa de justificación u otra eximente de responsabilidad penal.

El referido programa también incorpora diversos parámetros a observar al interior de los procesos jurisdiccionales, entre ellos, se destaca la necesidad de contar con defensores especializados en temáticas culturales, el auxilio de dictámenes especializados (particularmente antropológicos), el principio de buena fe en la consideración de los elementos culturales, así como la consideración de las especificidades étnicas y culturales a lo largo de todo el proceso, lo cual, además, es visto como parte consubstancial del derecho fundamental al acceso a la justicia.

Ahora bien, se debe precisar que la forma de Estado asumida por Argentina corresponde a la de una Federación, de modo que existe un ordenamiento jurídico nacional y, junto a él, 23 ordenamientos correspondientes a los Estados federados (provincias), cuyas realidades, unas de otras, son completamente diferentes. Si bien la Constitución Nacional proporciona una especie de "paraguas normativo" bajo el que las diversas provincias se regulan, nada obsta a que cada una de ellas fije diversos y muy variados "pisos mínimos" en lo que hace a la consideración del factor cultural, particularmente en sede penal.

Precisamente, esto último es el caso en provincias como Salta o Neuquén, donde su componente indígena es sustantivamente mayor y, consecuentemente, tanto la legislación como su jurisprudencia han también venido a dar cuenta de esta realidad. En Neuquén, como ejemplo, la denominada "Declaración de Pulmari" dispone, entre otros aspectos, el reconocimiento y respeto de la "identidad cultural de los pueblos indígenas neuquinos en la forma de resolver sus conflictos", a condición del respeto a los derechos humanos y al ordenamiento jurídico vigente (Restón, 2017, p. 163). En esta misma provincia, incluso, en 2015 fue integrado el primer jurado intercultural en la historia argentina en el que la mitad de sus integrantes fueron mapuches, llamados a juzgar un caso que involucraba una mujer

(1) El programa, así como los diversos “Dictámenes” a tomar en consideración frente a un posible delito culturalmente motivado, pueden consultarse en la página oficial del Ministerio Público de la Defensa: http://www.mpd.gov.ar/index.php/dictamenes [Fecha de consulta: 07/02/2021]. 
acusada de tentativa de homicidio (Relmu Ñamku), la que, finalmente, fue declarada inocente (Amaya, 2015, p. 1).

En el resto del país, y como regla general, el reconocimiento y valoración del componente cultural en sede penal suele darse mediante un apelo a la cláusula constitucional y a los tratados internacionales; ello ante la ausencia de una específica norma que confiera relevancia a tal factor, de modo tal que la jurisprudencia se ha encargado de incorporar estos elementos al "derecho viviente" $\mathrm{y}$, además, lo ha venido realizando recurriendo a las categorías tradicionales de la dogmática (tipicidad, antijuridicidad y culpabilidad), lo que ha permitido que, mediante dicho componente, puedan argumentarse situaciones de atipicidad, causas de justificación, errores de tipo o de prohibición o, incluso, estados de necesidad exculpantes (Stornelli, 2019, p. 23). Es importante resaltar que esto ocurre tratándose tanto de pueblos indígenas como de otras minorías étnicas, religiosas y culturales. De ahí que, salvo casos aislados (como Neuquén con su jurisdicción indígena), suela recurrirse a la "justicia ordinaria" en el tratamiento de la diversidad cultural.

Otro aspecto a señalar es el atinente a los límites en el reconocimiento a la diversidad cultural. A este respecto, al igual que muchos países que afirman el multiculturalismo, en aquellos casos "difíciles" en los que, de una parte, se alega el respeto a la identidad cultural y, de otra, se ven comprometidos otros derechos fundamentales (la integridad personal, la libertad, la autodeterminación del individuo, por citar tan solo algunos ejemplos), desde el punto de vista normativo se privilegia una posición garantista que afirma la no cesibilidad de derechos fundamentales frente al argumento de la cultura (Caesano, 2009, p. 11). Sin embargo, y como se verá a continuación, la jurisprudencia no ha sido constante y, en algunos casos pareciera asumirse una entronización del derecho a la cultura más allá de cualquier otro interés comprometido, una situación que ha generado un amplio debate y que no ha estado excepto de fuertes críticas (Cerezo Mir, 2006, p. 228; Caesano, 2009, p. 7; Grisetti y Kamada, 2013, p. 12).

La cuestión, sin embargo, permanece imprecisa y ello ante una situación inmanente a los propios derechos involucrados cuyos límites no siempre son evidentes, más aún, tratándose de cuestiones en las que se ven involucrados aspectos como la cultura, la identidad, la dignidad, el honor, la autodeterminación y otros tantos cuya lectura y definición solo puede darse a través de una "lectura intercultural" (Comanducci, 2005, p. 21).

Como se ha precisado, el caso argentino en materia de delitos culturalmente motivados asume la peculiaridad, no exclusiva, aunque si preponderante, de conjugar en gran medida el fenómeno migratorio con la pertenencia a una identidad étnica que suele ser indígena. De ahí que el apelo a un delito culturalmente condicionado se presente ante los tribunales tanto por individuos procedentes de 
países vecinos - cuyo componente indígena es destacado-, o por los propios indígenas argentinos.

De este modo, los diversos casos culturalmente orientados que se presentan en la Argentina tienen que ver con situaciones como: el consumo de ciertas sustancias estupefacientes, tal cual es, por ejemplo, el consumo de hojas de coca (habitual en las provincias del norte argentino); lesiones o, inclusive la muerte, derivados de tratamientos terapéuticos tradicionales; conductas al interior del núcleo familiar y en los que predomina una impronta autoritaria y paternalista del hombre para con su pareja e hijos; comportamientos con connotación sexual en los que se ven involucrados menores de edad; situaciones de poligamia; afrontas contra el honor interpretado en muy diversas formas; matrimonios infantiles; afectaciones sobre la propiedad, derivadas de una diversa forma de entender esta (sobre todo una interpretación colectiva/comunitaria), entre otros (Cerezo Mir, 2006, p. 230 y ss.; Benítez, 2016, p. 8; Villavicencio Terreros, 2012, p. 559 y ss.).

A continuación, presentaremos algunos casos resueltos por la jurisprudencia argentina en los que podrá advertirse el recurso a las categorías tradicionales dogmáticas y en las que el factor cultural ha sido objeto de valoración. Igualmente podremos ver la posición asumida por los tribunales en casos difíciles que involucran una ponderación entre derechos fundamentales y, en su oportunidad, presentaremos algunas reflexiones.

\section{II.1. Ausencia de tipicidad}

En este rubro podemos citar una de las primeras sentencias en Argentina que dio pauta a la valoración del factor cultural en sede penal. Se trata de una sentencia dictada en 1979 por el entonces juez federal Raúl Zaffaroni, relativa a la tenencia y consumo de hojas de coca por parte de un matrimonio de inmigrantes bolivianos radicados en Argentina desde hace más de veinticinco años (Juzgado Nacional en lo criminal, "Prieto Huanca, Timoteo y otra", sentencia del 30 de marzo de 1979).

El matrimonio fue denunciado y llevado a proceso. La defensa argumentó que el "coqueo", es decir, la práctica de mascar hojas de coca, correspondía a una antigua tradición andina enseñada por generaciones y aceptada como algo ordinario en la sociedad boliviana. Sin embargo, en aquel entonces, la legislación argentina prohibía el consumo de dichas hojas por considerarlas una especie de estupefacientes. El juez Zaffaroni, tras un diálogo intercultural con las partes y tras haber realizado diversas pesquisas, determinó, de una parte, que en el caso concreto no se verificaba una situación de peligro ni mucho menos una concreta lesión del bien jurídico tutelado por el tipo penal y que correspondía a la salud pública, por lo que la conducta, según argumentó el juez, resultaba atípica. 
En este punto, es importante resaltar cómo Zaffaroni presenta una adelantada crítica a las tendencias expansionistas del derecho penal (Silva Sánchez, 2001, p. 166 y ss.), manifestada a través de la creación de diversos tipos penales estructurados sobre la base del peligro (Grasso, 1986, p. 697; Catenacci, 2006, p. 1415 y ss.). En este caso, a través de la Resolución 162/74, publicada en el Boletín Oficial el 20 de octubre de 1975, la Secretaría de Salud Pública incluyó a las hojas de coca dentro de la categoría de estupefacientes; posteriormente, mediante la ley 20771 del 26 de septiembre de 1974, se aclaran los alcances del término dispuestos en el artículo 204 del Código Penal (CP), disponiéndose la tenencia o consumo de hojas de coca. A la par, cabe indicar que, mediante el decreto No 658 del 22 de marzo de 1978, la entonces Junta Militar dispuso un mayor rigor punitivo en cuanto a la portación y/o consumo de las hojas de coca (Abduca y Metaal, 2013, p. 5).

Como sabemos, en los casos de peligro concreto corresponde al juez la comprobación de una efectiva puesta en peligro del bien jurídico tutelado. El peligro es un elemento del tipo penal, indicado expresamente o, en algunos casos, implícitamente (Caterini, 2017, p. 46). En los casos de peligro abstracto, una cierta conducta indicada por el legislador (en este caso por la junta militar) se considera presuntamente riesgosa para el bien jurídico, con base en abstractas reglas de experiencia. Aquí no se requiere que el juez compruebe en concreto la efectiva peligrosidad, pues se da por supuesta. Por ello, el peligro no es un elemento del tipo, toda vez que la acción se configura con la mera conducta que se presume peligrosa y no corresponde al juez realizar la constatación específica del riesgo (Marinucci y Dolcini, 2015, p. 225; Cerezo Mir, 2002, p. 47).

En el caso concreto, la norma penal preveía expresamente una situación que, per se, venía considerada peligrosa (un delito de peligro abstracto), toda vez que la mera posesión y/o consumo de hojas de coca, sin ningún acreditamiento adicional, configuraba la situación de "peligro" dispuesta por la norma penal, no dando margen a ninguna interpretación adicional por parte del juzgador. Es importante recalcar que el contexto es el de la dictadura militar argentina y ello permite explicar el rigor hiper punitivo normativo ante un panorama en el que se pretendía "reorganizar" al país. En un párrafo posterior se verá cómo el juez de apelación, incluso, se pronuncia respecto de los comentarios vertidos por el juez Zaffaroni.

Por otra parte, y regresando al análisis de la sentencia en cuestión, el juez Zaffaroni, adentrándose en lo que vendría a ser su tesis del error de comprensión, agregó que la conducta desplegada por los agentes se ubicaba en la hipótesis prevista por el artículo $34.1 \mathrm{CP}$, el cual dispone, entre otras cosas, la no punibilidad del injusto penal no comprendido como resultado de un error o ignorancia no imputables. En efecto, el juez argumentó que los imputados se encontraban imposibilitados de comprender la prohibición dispuesta por la norma, toda vez 
que las particulares características de los agentes los habrían conducido a un error culturalmente condicionado, excluyendo, por tanto, cualquier reproche de culpabilidad. Los imputados, en efecto, al haber realizado dicha conducta durante toda su vida la habrían interiorizado como una conducta habitual; además, las condiciones de pobreza y marginación que acompañaban a los migrantes tanto en su país de origen como en la Argentina los habrían excluido de las oportunidades de poderse informar respecto de la ilicitud de su conducta. En consecuencia, no podía en el caso concreto reprochárseles la ilicitud de su actuar. Además, el juez indicó que el artículo 34.1 CP literalmente exigía la comprensión, es decir, la internalización de la norma y no el simple conocimiento de la prohibición.

Esta sentencia revela ya un prematuro reconocimiento del factor cultural en sede penal; sin embargo, debe indicarse que la misma fue revocada por la Cámara de Apelaciones en tanto que, a su mérito, la portación y el consumo de hojas de coca resultaban enteramente típicas conforme a la Ley de Estupefacientes (Cámara Nacional Federal Criminal y Correccional, Sala II, 16-09-1979). Además, el tribunal de apelación agregó que no correspondía al a quo determinar si el consumo de la hoja de coca era o no perjudicial para la salud, sino cumplir taxativamente con lo dispuesto por la legislación (Benítez, 2016, p. 18).

También es importante señalar que en 1989 se dictó la ley 23.737, aún hoy en vigencia, que precisamente en su artículo 15 dispuso una excepción en el consumo de estupefacientes para el caso del consumo de hojas de coca destinadas a la práctica del "coqueo" o para su empleo en infusión, la cual es claramente una hipótesis de exclusión de responsabilidad penal culturalmente orientada (Restón, 2017, p. 707).

Otro caso interesante involucró la valoración del dolo como elemento de la tipicidad. Como es sabido, sobre la valoración del dolo al interior de las categorías dogmáticas ha existido un debate extenso en el que, para cierto sector de la doctrina, vendría a ser considerado un momento esencial de la valoración del injusto penal y, por tanto, considerado al interior de la culpabilidad, mientras que, para otro sector, vendría a ser un elemento característico de la tipicidad (Mir Puig, 2016, p. 164; Bricola, 1960, p. 100; Donini, 1991, p. 211; Santamaria, 1961, p. 18).

En esta ocasión, el Tribunal argentino valoró el elemento dolo como un requisito típico dispuesto por la norma. El caso se refiere a la comunidad mapuche Lof Campo Maripe (Tribunal de Impugnación de Neuquén, "Campo, Juan Albino y otros s/usurpación artículo 181", sentencia 26 de abril de 2019) que, en 2014, invadió y ocupó el territorio de un conocido club náutico en la provincia de Neuquén por considerar que dicho club se encontraba emplazado dentro de su territorio ancestral. Los hechos fueron denunciados y un grupo del colectivo fue sujeto a proceso por los delitos de usurpación y turbación de la posesión (artículos 181, 
incisos 1, 3 y 56 del Código Penal). Los hechos fueron del conocimiento del Tribunal de Impugnación de Neuquén quien determinó la ausencia de dolo.

El Tribunal consideró que, mediante diversas acciones jurídicas, tanto el gobierno provincial como el nacional fueron reconociendo exigencias y necesidades de parte de los colectivos indígenas de Neuquén, incluyendo sus derechos sobre territorios ancestrales. Con base en ello, los imputados consideraron que los territorios ocupados les pertenecían, por lo que, en los hechos, no obraron con el dolo de usurpar o de realizar actos posesorios respecto de una propiedad ajena (en tanto consideraron que aquella era su propiedad).

Además, señaló el tribunal, en el caso particular se debía considerar la especial relación y cosmovisión que el pueblo mapuche tiene para con su territorio y con las diversas manifestaciones del derecho a la propiedad, incluyendo la posesión. En consecuencia, al requerir los tipos penales la presencia de un dolo específico y, toda vez que, el mismo resultó ausente, el Tribunal determinó absolver a los imputados (Restón, 2017, p. 138).

\section{II.2. Las causas de justificación}

El Juzgado Federal de apelación de Formosa, en el fallo "Astorga Ariel y otros s/ inf. artículo 194 C.P.A.", sentencia de 6 de diciembre de 2012, determinó la presencia del ejercicio de un derecho por el que no resultaba imputable a los involucrados el delito de entorpecimiento de transporte por vía terrestre (artículo $194 \mathrm{CP}$ ) del que eran acusados.

Los hechos correspondieron a la "toma" de una carretera por parte de un colectivo indígena perteneciente al pueblo pilagá. Los imputados señalaron que, con anterioridad, habían mantenido diversas reuniones con funcionarios públicos provinciales a efectos de obtener subsidios que mejoraran sus condiciones de vida. Tales subsidios no les fueron concedidos y, en consecuencia, realizaron el corte de ruta. Miembros del colectivo fueron detenidos y sujetos a proceso. El Tribunal de primera instancia condenó a los imputados por el delito dispuesto en el artículo $194 \mathrm{CP}$.

En apelación, la defensa argumentó que el juez de primera instancia no valoró en su debida medida los derechos reconocidos a los pueblos originarios por el Convenio 169 OIT. Además, resaltó que tampoco fue planteada una ponderación entre el derecho a la protesta y la libertad ordenada de tránsito, concediéndose solo importancia a la norma penal más no a los derechos fundamentales involucrados.

El Tribunal de Apelación reconoció, primeramente, la situación de vulnerabilidad estructural de las comunidades aborígenes argentinas, razón por la cual 
indicó que siempre que estas se vieran inmersas en un proceso jurisdiccional debía de analizarse la situación con especial atención y sin perder de vista los derechos que les asisten, particularmente, los indicados en el Convenio 169 de la OIT. Igualmente, dio razón a la defensa en el sentido de que el juez a quo no realizó una ponderación concreta frente a los derechos fundamentales involucrados, esto es, la libertad de expresión y manifestación, por un lado, y el libre tránsito por el otro.

Con basamento en lo anterior, el Tribunal de Apelación señaló que, frente a una protesta social y cultural, de ningún modo podía adoptarse un criterio criminalizador, más aún cuando se trataba de pobladores indígenas, quienes, precisamente, recurrieron a esa forma de protesta ante la situación de extrema necesidad que padecen y, frente a la cual, no hallaron respuesta por parte de las autoridades provinciales.

Citando a Zaffaroni (2005, p. 191), los jueces agregaron que resultaba necesario adoptar un criterio distintivo para el caso de los pueblos indígenas, pues no podía criminalizarse por igual a todos los que participan en una protesta social, ya que la culpabilidad debía valorarse individualmente. Para el caso en cuestión, se trataba de grupos étnicos que disponen "de una especial protección constitucional a partir de la Reforma del año 1994".

Adicionalmente, los jueces valoraron la propia solicitud del fiscal general, quien señaló que "de ninguna manera pueden resultar pasibles de persecución penal los protagonistas de una protesta social. No se trata de un problema del derecho penal, sino que nos encontramos ante reacciones sociales frente a reclamos insatisfechos de ciertos grupos que padecen sistemáticas violaciones a sus derechos esenciales" (dictamen de la Fiscalía General del 9 de mayo de 2012, citado en la propia sentencia).

Con base en lo anterior, el Tribunal determinó aceptar la apelación, concluyendo la ausencia de responsabilidad penal por parte de los implicados.

En este caso, planteamos algunos cuestionamientos relativos a las condiciones y límites bajo los cuales la diferencia cultural puede expresarse y reconocerse en un ordenamiento jurídico. De entrada, creemos peligroso circunscribir la identidad cultural a una suerte de "carta de triunfo" por la que es posible alegar cualquier pretensión sin límite, amparada en la propia cultura. El derecho internacional de los derechos humanos, así como los postulados de un multiculturalismo liberal defendido en diversos países, reconocen como límite de las expresiones culturales el respeto a derechos fundamentales, así como a normas mínimas de convivencia en las sociedades, lo cual implica, entre otras cosas, el respeto prima facie a los correspondientes ordenamientos jurídicos. 
Ciertamente, el derecho a la identidad cultural de diversas minorías étnicas, lingüísticas y religiosas supone una especial protección atendiendo a las condiciones de marginalidad y de desigualdad social en la que tales colectivos, por regla general, suelen ubicarse, mas ello no implica que tal protección reforzada se traduzca en una suerte de inmunidad penal. En el caso sub examine, podríamos plantearnos qué hubiese ocurrido si, durante la manifestación, se hubiere proferido violencia con afectaciones o puesta en peligro de bienes jurídicos fundamentales, ¿aun así podría argumentarse el ejercicio legítimo de un derecho?

Igualmente, el caso presentado creemos que abre dudas respecto de su connotación estrictamente cultural pues, en el caso particular, el análisis y la argumentación no se concentra en la conducta desplegada (lo cual es la esencia de un delito culturalmente motivado, es decir, una conducta que de acuerdo con normas interiorizadas se asume como prohibida, permitida u obligada frente a otro ordenamiento que disiente de ello), sino, más bien, en los propios sujetos que la realizan, lo que también podría dar elementos que sustentaran un derecho penal de autor y no del acto, como corresponde a un Estado constitucional y democrático de derecho.

\section{II.3. Error culturalmente orientado y culpabilidad}

Al interior de la culpabilidad, como se verá, la jurisprudencia argentina revela una tendencia gradual a considerar el factor cultural dentro de la figura del error, particularmente cuando el mismo recae en la creencia equivocada de considerar la conducta amparada por una causa de justificación (error de prohibición indirecto) y que, como resultado, deriva en la incomprensión de la antijuridicidad.

Como hemos adelantado, en América Latina la hipótesis referida suele englobarse dentro de lo que se conoce como "error de prohibición", el cual supone una falta de conocimiento o de comprensión respecto de la ilicitud de una determinada conducta. El error será directo cuando recae en el desconocimiento de una norma prohibitiva de la conducta e indirecto cuando se sustenta en la creencia de actuar bajo el amparo de una causa de justificación. En ambos casos, puede ser evitable o inevitable con consecuencias diversas, según sea el caso (Stornelli, 2019, p. 14).

Al interior del error de prohibición directo (aunque también se admite en los casos de justificación putativa), la doctrina -liderada por los aportes de Raúl Zaffaroni- ha desarrollado la idea del error "culturalmente orientado", cuyo postulado base se relaciona con una dificultad o impedimento del individuo, derivado de su condicionamiento cultural, para poder no ya "conocer" sino comprender e interiorizar las razones por las que una determinada conducta es asumida 
como injusta. De este modo, la norma puede ser conocida por el sujeto, pero no susceptible de exigírsele su comprensión (internalización) derivado de un condicionamiento cultural en el que existen valores diversos e, inclusive, incompatibles (Zaffaroni, 2005, p. 533; Villavicencio Terreros, 2011, p. 559).

Un primer caso que presentamos se refiere precisamente a una alegada causa de justificación putativa, es decir, un error sobre una causa de justificación, resuelto por el Tribunal Superior de Justicia de Neuquén en sentencia del 12 de marzo de 1999 ("Puel s/daño"). Los hechos se refieren a un indígena mapuche que profería diversos daños a una serie de estacas limítrofes ubicadas en el territorio de la propia comunidad. El indígena fue detenido y sometido a proceso. En primera instancia se le condenó por el delito de daño. En apelación, el Tribunal Superior de Justicia determinó que, si bien la persona creía actuar bajo el ejercicio legítimo de un derecho (artículo 34, inciso $4 \mathrm{CP}$ ), en realidad no se presentaba tal situación, ya que las tierras no eran propiedad suya, sino de la comunidad y que, en todo caso, las estacas habían sido colocadas con la respectiva autorización; sin embargo, el Tribunal Superior consideró que el a quo omitió tomar en consideración la pertenencia cultural del inculpado, en tanto indígena mapuche y cuyas características culturales habrían condicionado su error que, a juicio del Tribunal, no le era enteramente imputable atendiendo a diversos estudios antropológicos que corroboraban la especial dinámica tradicional que se presenta entre los indígenas mapuches, el territorio y su identidad. Con base en lo anterior, el Tribunal Superior determinó absolver al imputado.

Otro ejemplo en el que fue alegada la presencia de un error, en este caso de prohibición invencible, corresponde a la sentencia del 4 de diciembre de 2013 del Tribunal Oral en lo Criminal Federal No 1 de la Plata, referente a una situación de reducción en servidumbre ("Hoyos Noguera, Juan Pablo y otros s/inf. artículos 119 inc. F y 145 ter del Código Penal"). En este caso, una menor de 11 años fue trasladada por una pareja desde Bolivia para dedicarla a tareas domésticas y al cuidado de los niños. A la menor se le tenía impedido abandonar la casa y disponer libremente de su tiempo; igualmente, venía sometida a jornadas laborales de más de quince horas durante toda la semana y sin remuneración alguna. Esta situación llevó a la menor a requerir atención hospitalaria y, tras recibirla, dio pauta a una denuncia con el posterior procesamiento de la pareja implicada.

El Tribunal Oral determinó que la menor había sido colocada en una situación de servidumbre contraría a la dignidad inherente de todo ser humano por lo que condenó a la pareja responsable. Durante el proceso, la defensa argumentó la presencia de un error de prohibición invencible que, además, se encontraba culturalmente condicionado sosteniendo que, en Bolivia es frecuente que, como consecuencia de la enorme pobreza y desigualdad, a los niños se les ocupe en 
tareas domésticas desde temprana edad, con horarios continuos, sin remuneración alguna y que, incluso, sea normal que deban abandonar la escuela. Inclusive, señaló la defensa, los propios imputados se habían colocado durante su infancia en una situación similar a la de la víctima por lo que, en tal contexto, los imputados desde pequeños habían internalizado tales pautas culturales y, por tanto, resultaba lógico que no pudieran representarse la punibilidad de su conducta.

El Tribunal Oral (así como el de apelaciones, que posteriormente se pronunció) señaló que no era dable argumentar una situación de error, ni mucho menos su carácter de invencibilidad, en razón del número de años que la pareja tenía viviendo en la Argentina y, adicionalmente, en atención a que la propia legislación de Bolivia sancionaba la misma conducta. Sin embargo, el Tribunal valoró la presencia de elementos culturales característicos de la realidad boliviana, así como de los propios imputados, reconociendo en ellos un cierto condicionamiento determinado por sus historias de vida que, en efecto, incidía en la comprensión de la antijuridicidad; no obstante, concluyó que el error no resultaba invencible. En consecuencia, la pareja fue declara responsable de los hechos imputados, pero modulándose la punibilidad con el mínimo legal para el tipo penal en cuestión (3 años) en atención a los particulares motivos que determinaron su actuar (artículo $41 \mathrm{CP})$.

En este caso puede apreciarse ya una situación que involucra la colisión de derechos fundamentales; de una parte, la identidad cultural que considera "aceptable" la realización de una determinada práctica, de otra parte, una pluralidad de derechos fundamentales del menor de edad, tales como la libertad, la educación, el libre esparcimiento y desarrollo de la personalidad, el interés superior del menor, sus derechos como niña y como mujer, así como en términos amplios el derecho a una vida digna.

Sin lugar a dudas, el presente evento podría catalogarse como un "caso difícil" ante las implicaciones jurídicas y, por qué no, morales y sociales que involucró. No obstante, consideramos que, en estricto sentido jurídico, la sentencia evidencia una aplicación adecuada de la ley penal, pues, de una parte, los jueces arriban a la conclusión de una responsabilidad penal, frente a la cual el argumento cultural no tiene cabida ya que involucró la lesión de derechos de orden fundamental. Por otra parte, ello no desconoció la incidencia que el factor cultural pudo tener en la comprensión de la conducta desplegada por los agentes, haciéndola no inevitable, pero, al menos, sí reconociendo su condicionamiento por lo que, en el caso particular y, como lo realizó el tribual, no cabría el mismo tipo de reproche que podría hacerse frente a una persona no influenciada por el elemento cultural.

Otro caso resuelto por la jurisprudencia argentina en el que se plantearon argumentos de orden cultural y que fue resuelto apelando a un error de prohibición 
(culturalmente motivado) es el correspondiente a la sentencia de 3 de agosto de 2012 de la Cámara Federal de Resistencia ("Santillán, Agustín y otros s/interrupción de los medios de comunicación y transporte por tierra, artículo 194 Código Penal"). Los hechos consistieron en la "toma" de una ruta nacional y la correspondiente interrupción del tráfico vehicular por parte de un colectivo indígena (wichi) que, a través de tal conducta, planteaban diversas demandas frente a la autoridad provincial. El colectivo fue denunciado y sujeto a proceso por un "delito contra la seguridad del tránsito y de los medios de comunicación" (artículo $194 \mathrm{CP}$ ).

El caso llegó al conocimiento de la Cámara Federal de Resistencia quien revocó el auto de procesamiento por considerar que, en el caso concreto, se verificaba una situación de error (nuevamente, una justificación putativa). En efecto, la defensa argumentó que, adicionalmente a los derechos fundamentales reconocidos a todo individuo (incluida la libre manifestación), al colectivo en cuestión asistían los derechos indígenas dispuestos por el Convenio 169 OIT, lo que implicaba el deber de la autoridad para juzgar tomando en consideración la especial idiosincrasia de estos individuos. Adicionalmente, se constató que dos años antes el colectivo se había manifestado del mismo modo, incluso, con una duración de quince días, logrando mediante tales acciones la respuesta favorable a diversas peticiones. Con base en lo anterior, la Cámara Federal dio razón a los argumentos de la defensa en el sentido que, el colectivo indígena habría actuado bajo la creencia de haberse encontrado amparado en un derecho, mismo que le fue reconocido dos años atrás bajo idénticas condiciones. Además, la Cámara Federal incluso consideró que el procesamiento de los implicados bien podría dar pauta a interpretarse como una "criminalización de la protesta social".

Más allá de nuestra personal complacencia por privilegiar el diálogo y el consenso frente a la represión de la protesta social, consideramos que, en este caso, nuevamente, existe una especie de forzadora argumentativa, fundada en el factor cultural, por el que se intenta justificar la conducta desplegada por los imputados. Creemos que, más allá de un apelo al elemento cultural, el caso muestra una constante en América Latina, que es el ejercicio de la protesta social como instrumento de negociación frente a la autoridad pública. De este modo, podríamos alegar que la misma protesta bien habría podido ser realizada por profesores, estudiantes, médicos o colectivos feministas y, dependiendo sobre todo de una cuestión de política criminal, habría sido valorada la conveniencia, o no, del ejercicio de la acción penal. En tal sentido, el apelo a los elementos culturales parece ser demasiado forzado, pudiéndose haber resuelto este caso bajo otro tipo de consideraciones.

Un caso de gran repercusión pública en la Argentina y que deja claramente apreciar el conflicto que se suscita entre la identidad cultural y el respeto a los derechos fundamentales del individuo es el correspondiente al fallo "C/C Ruíz, José 
ARgentina e ItALIA ANTE LA DiVERSIDAD CULtURAL: VALORACión EN SEDE PENAL DEL FACTOR CULTURALMENTE RELEVANTE - MARIO CATERINI Y

Fabián - Recurso de Casación", resuelto por la Corte de Justicia de la Provincia de Salta el 29 de septiembre de 2006 (Rabbi y Baldi, 2011, p. 15).

El caso se refiere al procesamiento de un indígena wichi por el delito reiterado de abuso sexual cometido en contra de una menor que, por lo demás, se encontraba bajo su protección al ser su hijastra y que, como resultado, resultó embarazada. El Tribunal de primera instancia condenó al imputado, la defensa presentó diversos recursos y, finalmente, el asunto llegó ante la Corte de Justicia de Salta.

La defensa sostuvo que la conducta se encuadraba dentro de la hipótesis de un error de prohibición culturalmente motivado, en tanto que para la ancestral costumbre wichi es permitido que un hombre tenga relaciones sexuales con una mujer a partir de su primera menstruación, dichas relaciones fueron siempre consensuadas en el caso sub exánime, y, a la par, se argumentó que existía en la comunidad una forma diversa de entender al matrimonio, en tanto que, para los wichi, la "unión" existía tanto con la madre como con la hija (siempre que la hija hubiera sido producto de un matrimonio diverso). Lo anterior, sostuvo la defensa, conforman un estilo de vida diverso conocido como "matrimonio privignático", por lo que el imputado actuó siguiendo una pauta cultural considerada correcta y, por tanto, no tuvo comprensión del incumplimiento de una norma jurídica.

La Corte de Justicia de Salta concluyó que, de una parte, el contexto cultural del imputado incidió directamente en su culpabilidad, a través de una distorsión en la comprensión del injusto penal, ya que, para la propia comunidad, el matrimonio privignático era considerado un modo de vida aceptable y precisamente esta situación habría sido la que impidió al imputado comprender la criminalidad de su conducta.

De otra parte, la Corte consideró que al imputado se le habría visto vulnerado su derecho a la identidad cultural indígena (tutelado constitucionalmente) al no verse valorada integralmente su perspectiva cultural por parte del tribunal de primera instancia. Esta omisión, señaló la Corte, repercutió directamente en el derecho fundamental a una defensa adecuada, violentando en su conjunto los artículos 75, inciso 17, de la Constitución nacional, así como los artículos 15 y 18 de la Constitución de Salta (que garantiza el respeto a la identidad de los pueblos indígenas); en consecuencia, la Corte resolvió dar lugar al recurso de casación y ordenar la nulidad del auto de procesamiento.

Es importante señalar que la votación de la Corte de Justicia de Salta no fue unánime. La disidencia manifestó que el acceso carnal reiterado en un menor hasta procurarle su embarazo, sustentado en un presunto consentimiento y en la existencia de una cultura que legitima tal práctica, no podía verse tutelada por los principios constitucionales al ser completamente contraria al "plexo de derechos 
humanos internacionalmente reconocidos". Además, la disidencia advirtió de los peligros del relativismo cultural al indicar "sostener que en la conducta bajo examen no hay agresión porque se trata de otra concepción cultural de 'integridad sexual' o por no haber sufrido ningún daño psico-emocional la supuesta víctima, significa apartarse del concepto de 'integridad personal', del cual la integridad sexual es sólo uno de los componentes".

En nuestra opinión, se evidencia un discurso parcial en el que solo cuenta la preeminencia del factor cultural. En el caso en cuestión, el análisis pudo haberse delimitado a la valoración del peso y condicionamiento de la cultura en el comportamiento desplegado, determinando si tal factor resultaba insuperable, o no, a fin de determinar la responsabilidad del inculpado, y, en su caso, modular la individualización de la sanción a partir de una circunstancia atenuante, siempre que efectivamente se hubiere acertado la incidencia del factor cultural. Más allá de cualquier otra consideración, corresponde a los jueces analizar estrictamente los elementos jurídicos de los que disponen y, a partir de ellos, si se actualiza una circunstancia que pueda dar lugar a la ausencia de responsabilidad o a su atenuación, aplicarla en consecuencia.

Sin embargo, la sentencia resulta sumamente superficial y no llega a individualizar con certeza la forma, el modo y la intensidad en la que el factor cultural, en su caso, incide en el comportamiento desplegado. Más allá de haber podido ser un ejemplo paradigmático de ponderación entre derechos, la sentencia ha pasado a ser un buen argumento para los críticos del multiculturalismo, que alegan el peligro de defender una interpretación sumamente amplia e irrestricta de las prácticas culturales (Pozze, 2017, p. 137).

Una posición como la anterior, y que el fallo en cuestión parece envolver, no puede conjugarse en armonía con nuestra interpretación acerca de los derechos fundamentales básicos porque parece entronar el derecho a la identidad cultural por encima de cualquier otro derecho, desconociendo los respectivos límites que lo configuran y que, en un contexto liberal, constitucional y democrático de derecho, lo determinan, ante todo, el respeto a los demás derechos fundamentales (Tarducci, 2013, p. 12).

El caso ilustra claramente la advertencia que ha sido formulada por diversos teóricos sobre la necesidad de incorporar no solo restricciones externas en ámbito multicultural, sino también internas al interior de los propios grupos y subgrupos culturales. También da pautas para analizar cómo la identidad queda definida por una pluralidad de condiciones y no solo por una dominante, de tal forma que la menor de edad del presente caso no solo es una indígena a la que rodea una práctica cultural, el matrimonio privignático, sino que también es una niña, una mujer, 
una persona, una escolar, una hija, una víctima, entre otras identidades que, sin embargo, no fueron ponderadas en el caso examinado.

Frente a este ejemplo, podemos señalar uno diverso que también involucró la colisión de derechos fundamentales, pero con una argumentación diversa en la que primó la idea de la irreductibilidad de estos frente a argumentos culturales. El caso es el corresponde al dictado por la Cámara Nacional de Apelaciones en lo Criminal y Correccional de la Ciudad de Buenos Aires, resuelto el 18 de marzo de 2002 ("Su Shao Mei y otra").

Los hechos refieren a una inmigrante china, menor de edad, que, de acuerdo con testigos, era encerrada en un sótano por días enteros, en completa oscuridad, así como sujeta a múltiples tratos cercanos a la esclavitud. La menor tenía prohíbo salir y, frecuentemente venía castigada por sus padres con sanciones psicológicas y corporales asimilables a tortura. Los hechos fueron denunciados y los padres sujetos a proceso. El Tribunal de Primera Instancia resolvió que los padres eran responsables del delito de reducción análoga a la servidumbre (artículo $140 \mathrm{CP}$ ) frente a lo cual estos interpusieron apelación.

Los argumentos dados por la defensa planteaban la existencia de un error de prohibición culturalmente condicionado atendiendo a las raíces culturales chinas de los involucrados. En efecto, la defensa señaló que en la cultura popular china es frecuente que los padres mantengan una enérgica disciplina para con los hijos y que, incluso, sean frecuentes los castigos corporales. Se indicó que, bajo la propia experiencia vivida por los padres, estos no podían prefigurarse que el trato proporcionado a su hija pudiera ser inadecuado e, incluso, sancionado penalmente, por lo que, se alegó, no obraron con la conciencia de la ilicitud.

Frente a estos argumentos, la Cámara Nacional de Apelaciones señaló que el ordenamiento argentino reposaba en el principio de la inviolabilidad de los derechos fundamentales básicos, los que de ningún modo podían verse menoscabados apelando a la cultura o al origen nacional, ya que, de aceptar ello, se conduciría a la irracional conclusión de tener que admitir la tortura, la mutilación genital femenina o la creación de mafias con penas de muerte a partir del argumento de que una cierta cultura así lo permite. Cuestión última que ni siquiera se verificaba en el caso de la legislación china la que tampoco permitía justificar un tratamiento de este tipo para con los hijos, ni que tampoco se demostraba (como argumentó la defensa) una práctica difusa en la sociedad contemporánea de ese país. Con base en estas consideraciones, la Cámara Nacional de Apelaciones determinó el procesamiento de los imputados (Benítez, 2016, p. 22). 


\section{El caso italiano}

La República italiana es también un claro ejemplo de un Estado multicultural; sin embargo, su pluralidad se debe fundamentalmente al fenómeno migratorio. Otrora característico país migrante, hoy día Italia es uno de los principales destinos para miles de personas que escapan del hambre, la pobreza, la guerra y las persecuciones.

En sede penal, los operadores jurídicos italianos deben también afrontar los problemas derivados de las antinomias normativas y culturales que los sujetos inmigrantes cargan con sí y que no pueden, sencillamente, desprender de su identidad tal cual fuera una vestimenta u otro objeto similar. Así, Italia se enfrenta al cúmulo de expresiones y manifestaciones culturales procedentes de Pakistán, Marruecos, Túnez, Albania, Argelia, Turquía, China, Ucrania, Polonia, Sri Lanka, Bangladesh, entre otros.

La resultante, en ámbito penal, se traduce en delitos culturalmente motivados que frecuentemente involucran aspectos como: delitos contra la libertad sexual; contra la familia (por ejemplo, el incesto, matrimonios poligámicos, violencia); actos de venganza y de "reparación" frente al "honor familiar"; delitos contra la persona (lesiones, mutilaciones o deformaciones "rituales" del cuerpo; delitos en materia de estupefacientes, entre otros (Maldonado Smith, 2020, p. 57).

Frente a esta diversidad cultural, adelantamos, el sistema jurídico italiano ha respondido de un modo ambivalente (Grandi, 2011, p. 15 y ss.), lo que nos permite insinuar una ausencia de dirección frente a la multiculturalidad que, en algunos casos, conjuga el reconocimiento del factor cultural como un elemento meritorio de tutela, incluso penal, y, en otros, como un elemento análogo a la peligrosidad visto como un riesgo a la seguridad y a la propia "identidad italiana" (Caterini, 2015; De Maglie, pp. 32-33).

A propósito de dicha identidad, la historia italiana ha estado también acompañada por ese "velo" de la construcción nacional fundada en la idea de la homogeneidad; como muestra, puede citarse la "Relazione al Re" en la que el Ministro Guardasigilli, con motivo de la propuesta de Código Civil, señalaba (aún en 1943): "El Estado se nos presenta como la misma nación en él representada, es decir, como una unidad no solo social, sino incluso étnica, ligada con vínculos de raza, de lengua, de costumbres, de tradiciones históricas, de moral, de religión" (De Maglie, 2010, p. 34).

Una impronta semejante es la que revela el Código Penal italiano (CP), mejor conocido como Código Rocco, que, sea dicho de paso, fue adoptado en el año de 1930 bajo un contexto autoritario en el que se privilegiaban los valores e 
identidades asumidas como "comunes" por la sociedad italiana. Dicho Código ha sido objeto de múltiples reformas, aunque no puede negarse que el perfil autoritario y la prevalencia de cierta identidad aún se mantiene presente, particularmente mediante la presencia de elementos normativos cuyo contenido solo puede determinarse a partir de un reenvío a la cultura y a los valores italianos (Donini, 2008, p. 82; Caterini, 2011, p. 163), tal es el caso de elementos como el "vilipendio" (artículos 290, 291, 292, 403 y 404 CP), el "común sentimiento del pudor" (artículo 529, inc. 1 CP), la "moral familiar" (artículo 565 CP) o la "pública decencia" (artículo 726, inc. $1 \mathrm{CP}$ ).

En ámbito constitucional sucede algo diverso. La Constitución Italiana de 1947 es, sin lugar a dudas, una Constitución ampliamente garantista en el que la tutela de los derechos fundamentales cobra especial importancia. Si bien en el ámbito multicultural no existe una cláusula expresa de su reconocimiento, este puede intuirse a través de diversas disposiciones (Grosso, 2006, p. 129), entre ellas: el principio de igualdad y su corolario de no discriminación por raza, lengua o religión (artículo 3), el reconocimiento y defensa de las minorías lingüísticas (artículo 6), el pluralismo religioso (artículos 8 y 9), la tutela de la cultura en extenso (artículo 33), así como la pluralidad política (artículo 4) e institucional (artículo 114).

Dentro de las fuentes normativas de orden internacional incorporadas al ordenamiento italiano, que, igualmente, disponen de elementos que permiten valorar el factor cultural, podemos señalar: la Convención Internacional sobre la eliminación de todas las formas de discriminación racial (artículos 1, 2, 5 y 7), ratificada el 21 de diciembre de 1965; el Pacto internacional de Derechos Civiles y Políticos (artículo 27), ratificado el 23 de marzo de 1976; el Tratado sobre la Unión Europea (artículo 2), ratificado el 2 de agosto de 2008; la Convención Unesco sobre la protección y la promoción de la diversidad de las expresiones culturales (artículos 2 5, 6, 7 y 8), ratificada el 19 de mayo de 2007; y la Convención Europea para la salvaguarda de los derechos del hombre y de las libertades fundamentales (artículos 8, 9 y 14), ratificada el 4 de agosto de 1955.

A pesar de estas disposiciones, hemos indicado que el caso italiano presenta diversas ambigüedades, fundamentalmente en el ámbito de la legislación ordinaria donde podemos encontrar normas que promueven la diversidad cultural y, a la par, normas que la criminalizan y que, incluso, poseen un perfil subjetivo que parecería tener como destinatarios específicos a musulmanes, africanos, gitanos $\mathrm{y}$, en general, inmigrantes no comunitarios.

En el caso de la legislación "abierta" a la multiculturalidad, puede citarse el Texto Único sobre la inmigración (d. lgs. de 25 de julio de 1998, n. 286) en el que se prohíbe toda forma de discriminación contra la población migrante (artículo 43), se promueve el reconocimiento y valoración de las expresiones culturales de los 
extranjeros (artículo 42) y se dispone una educación fundada en las diferencias lingüísticas y culturales como elemento para la construcción de una sociedad tolerante, inclusiva e intercultural (artículo 38).

Otro ejemplo de esta normativa es la "Carta de los valores, la ciudadanía y la integración", elaborada por el Ministerio del Interior y que reconoce la diversidad cultural de Italia disponiendo, además, directrices de trato a observarse para con los inmigrantes, basadas en los principios de la acogida, la integración y la regularización del fenómeno migratorio a fin de garantizar la protección del pluralismo cultural y religioso. Dicha Carta, por ejemplo, dispone la prohibición de toda forma de discriminación (punto 1), instituye la extensión de derechos y la protección hacía los inmigrantes (punto 3) y, promueve una integración de los migrantes que sea respetuosa de la propia identidad de cada individuo (punto 4).

Símilmente, el d. lgs. de 1 de septiembre de 1998, № 333, se refiere al trato proporcionado a los animales durante su sacrificio, disponiendo reglas de excepción a aplicarse para aquellos casos vinculados a los ritos y celebraciones religiosas (artículo 5, inciso 2) e, igualmente, la ley de 20 de julio de 2004, n. 189, indica que no se considerará un "delito contra los sentimientos de los animales", a aquellas manifestaciones históricas y culturales que hayan sido autorizadas por las regiones competentes; en ambos casos, como puede verse, se trata de normas de excepción fundadas en el respeto a la diversidad cultural, particularmente de grupos religiosos como lo son musulmanes y judíos (Roccella, 2000, p. 201 y ss.).

Junto con disposiciones de esta envergadura, el ordenamiento italiano conjuga otras tantas sustancialmente contradictorias, emanadas particularmente en tiempo reciente. De este modo, ha sido elaborado ex profeso un tipo penal hiper criminalizador dirigido a la sanción de la mutilación genital femenina (artículo 583 bis $\mathrm{CP})$, del todo innecesario ante la presencia de otros tipos penales aplicables al caso y que refieren más bien a una dedicatoria a la población musulmana, asiática y africana existente en Italia (Fornasari, 2008, p. 194; Caterini, 2020, p. 123; Longobardo, 2001, p. 130; Provera, 2018, p. 193). Misma lógica aplicable al delito de empleo de menores en la mendicidad (artículo 600 octies $\mathrm{CP}$ ) dirigido a la población gitana (Scalia, 2009, p. 1207; Scafi, 2010, p. 631; Scoletta, 2009, p. 113) o, incluso, el paradigmático delito de inmigración clandestina (artículo 10 bis del Texto Único de Inmigración) que sanciona no una conducta concreta sino una condición: la de ser un inmigrante ilegal en Italia, norma típica de un derecho penal de autor (Moccia, 2008; Cavaliere, 2017, p. 155; Gatta, 2015, p. 189; Manna, 2011, p. 446).

Igualmente, en el 2018 fue emanado el denominado "Decreto Salvini" (d.l. de 4 de octubre de 2018, n. 113), consistente en un paquete de medidas legislativas de amplia extensión (protección internacional, inmigración, ciudadanía, seguridad pública y crimen organizado) y que, en gran medida, disponía de un perfil anti 
inmigratorio (extracomunitarios). Entre las medidas que disponía, pueden citarse: la abolición de la protección humanitaria; una mayor restricción de acceso al territorio nacional y, para aquellos ya ingresados, mayores requisitos en su regularización; la ampliación de los supuestos por los que se justifican las "prohibiciones de acceso" a ciertos lugares (D.A.SPO); la pérdida de la ciudadanía por la comisión de ciertos delitos; entre muchos otros. El Decreto Salvini, finalmente, fue modificado en octubre de 2020 por un nuevo gobierno; sin embargo, refleja claramente la posición que un sector importante tiene frente a la diversidad cultural, particularmente, la diversidad no europea.

En el siguiente apartado mostraremos que las contradicciones existentes no solo operan desde el punto de vista legislativo sino también en la aplicación del derecho. Igualmente, daremos cuenta cómo el ordenamiento italiano, en algunos casos, da pauta al reconocimiento del factor cultural al interior de las categorías tradicionales de estudio de la dogmática penal (tipicidad, antijuridicidad y culpabilidad), así como los problemas a los que se han enfrentado los operadores jurídicos en aquellos casos en los que se presenta una colisión de derechos fundamentales.

\section{III.1. Ausencia de tipicidad}

Italia ha tenido ocasión de tratar en sede jurisdiccional una de las manifestaciones culturales que más recelos suscitan al interior del multiculturalismo y que no es otro que la mutilación genital femenina (MGF). En diversos casos, la jurisprudencia ha considerado la ausencia de tipicidad ante la exigencia del dolo específico que el tipo penal italiano ex profeso (artículo 583 bis CP) requiere (sobre el dolo "típico", Mir Puig, 2016, p. 164; Santamaria, 1961, p. 18).

Un primer caso se refiere al de una pareja de inmigrantes nigerianos, residentes en Italia, los que decidieron llevar a su país de origen a la hija menor de edad a fin de que le fuera practicada la MGF. Más tarde, y al regresar a Italia, fue descubierto este hecho, por lo que la pareja fue denunciada.

El Tribunal de Menores de Piemonte y Valle d'Aosta (sent. 17 julio 1997, cit. Bouchard, 2000, p. 22; Crocco, 2015, p. 133 y ss.) determinó que el caso debía ser archivado, tanto por falta de competencia como por ausencia de dolo en la conducta. Este razonamiento partió de la consideración del propio Ministerio Público quien alegó que, de una parte, los hechos habían ocurrido en el extranjero donde dicha conducta era considerada lícita. Además, aún y cuando la conducta pudiera hipotéticamente ser perseguida, señaló, resultaría atípica, toda vez que habría sido realizada bajo la convicción de que la misma era una conducta lícita y ello habría conducido a un error inevitable que, como consecuencia, habría excluido el dolo. 
De nueva cuenta, y como hemos señalado anteriormente, se evidencia una posición en la que el dolo es valorado como elemento constitutivo de la tipicidad. El Tribunal se acogió a los argumentos del fiscal y determinó que, en efecto, no se verificaba el dolo requerido por el tipo penal por lo que la conducta resultaba atípica.

Otro caso de MGF fue resuelto en 2010 por el Tribunal de Verona (sent. 14 de abril de 2010, n. 979; Pecorella, 2011, p. 853). Se trata del caso “Obaseki", en el que una mujer nigeriana realizaba la MGF bajo solicitud de diversos miembros de la colectividad nigeriana residente en Italia. En una de las diversas ocasiones que realizó la práctica, la mujer fue sorprendida y denunciada, junto con la pareja de nigerianos que en aquella ocasión practicaron la MGF a su hija menor de edad. El Tribunal de Verona, al conocer del caso, determinó que la conducta no podía encuadrarse exactamente como un tipo de MFG porque las heridas ocasionadas consistían tan solo en mínimas incisiones que no podían ser calificadas dentro de la descripción típica requerida por la norma (infibulación, escisión, circuncisión o cualquier otro tipo de mutilación); sin embargo, sí podían ser consideradas como lesiones genitales, resultándole aplicable la hipótesis de menor punibilidad dispuesta por la norma penal (artículo 583 bis, inciso 2). En razón de ello, se condenó a los imputados.

La defensa presentó recurso ante el Tribunal de Apelación de Venecia (sent. 23 de noviembre de 2012, № 15485), donde se concluyó que no existía responsabilidad penal por ausencia de dolo (Basile, 2013, p. 24 y ss.). El Tribunal señaló que el tipo penal dispuesto por el artículo 583 bis requería un dolo específico que, en el caso particular, no se presentaba. Indicó: "no se concluye ninguna referencia de haber actuado con el propósito de disminuir las funciones sexuales (...) dada la naturaleza de la conducta requerida y señalada, por lo que es absolutamente inidónea, por su consistencia, a revelar la intención en el sentido señalado" (Basile, 2013, p. 13).

En efecto, la norma requería que la conducta hubiese estado dirigida a "dañar las funciones sexuales", lo que, en el caso sub examine, no se presentaba, toda vez que la función antropológica e identitaria de la conducta desplegada no tenía en modo alguno esa finalidad, antes bien, la de "integrar" o "permitir" a la menor ser parte de un grupo social. Los padres, argumentó el Tribunal, más allá de buscar intencionadamente dañar a la menor, actuaban bajo la firme convicción de estar procurándole un beneficio, de acuerdo con el espectro identitario que para tal cultura implicaba la práctica de la MGF. En consecuencia, se determinó absolver a los imputados.

Sobre estos casos, consideramos que, en rigor, asiste razón a la jurisprudencia italiana al determinar la atipicidad, más bien como resultado de una falencia 
legislativa en la que el tipo penal requiere de un dolo específico sumamente complejo de acreditar, toda vez que, en los casos prácticos resultaría, si no imposible, al menos extremadamente complejo el acreditar que se está obrando precisamente con la finalidad de disminuir las funciones sexuales. No obstante, y en diversas ocasiones, hemos manifestado nuestra posición frente a una práctica como la MGF cuando esta viene realizada en menores de edad que no tienen posibilidad alguna de manifestar su libertad (Maldonado Smith, 2020, p. 108).

Igualmente, en Italia ha sido posible aducir la ausencia de tipicidad a partir de la propia cláusula del "motivo justificado" presente en diversos tipos penales. Uno de estos casos es el que resolvió el Tribunal de Cremona en 2009 (sent. 19 de febrero de 2009, № 15) referente a un inmigrante indio perteneciente a la religión "Sikh", el cual fue sorprendido en un centro comercial portando sus atuendos tradicionales, incluyendo el característico cuchillo kirpan. El individuo fue procesado por el delito dispuesto en el artículo 4, inc. 2, de la 1.18 de abril de 1975, que sanciona la portación de armas comunes e impropias, salvo "justificado motivo". El Tribunal consideró que la portación del cuchillo debía de ser analizada sobre la base de su uso natural y que, por tanto, en el caso concreto el kirpan no constituía un arma propia, aunque sí una impropia. En una segunda argumentación, analizó el significado del kirpan a la luz de la religión Sikh, de acuerdo con la cual el cuchillo es ante todo un "símbolo" de la fe religiosa y de la "resistencia al mal". A partir de ello, el Tribunal relacionó la portación de dicha arma con el artículo 19 CN que tutela la libertad de religión, concluyendo que, en el caso concreto, se verificaba un motivo justificado (Provera, 2010, p. 978; Pistorelli, 2008, p. 2113).

Otro caso similar se presentó en el mismo Tribunal de Cremona (sent. 28 de noviembre de 2008, n. 78) referente a una mujer de religión musulmana que, al acudir a la Corte de Apelación a presenciar el juicio de su marido, fue requerida para que se retirase el burka, situación que realizó pero que, sin embargo, le ocasionó el ser denunciada y sujeta a proceso penal por el delito dispuesto en la l. $\mathrm{n}$. 152/1975, artículo 5, que prevé "el uso de cascos protectores o de cualquier otro medio dirigido a hacer difícil el reconocimiento de una persona en lugar público o abierto al público sin justificado motivo". El Tribunal de Cremona consideró que el uso de del burka era sin lugar a dudas un motivo justificado a la luz del artículo 19 $\mathrm{CN}$, por lo que se verificaba una situación de atipicidad, toda vez que dicho atuendo constituía una expresión característica de la tradición cultural musulmana usado con una finalidad diversa a la que la norma penal buscaba evitar (De Maglie, 2010, p. 173).

\section{III.2. Las causas de justificación}

En el caso italiano, la antijuridicidad ha sido la categoría de análisis penal en la que el factor cultural ha tenido menos espacios de reconocimiento y ello debido 
a que, normalmente, las conductas constitutivas de delitos culturalmente motivados tienden a incidir en bienes jurídicos de especial tutela para el ordenamiento italiano (por ejemplo, la integridad física, la libertad sexual, la dignidad, la igualdad, etc.), por lo que sería difícil justificar la ofensa con las tradicionales causas de justificación, más aún porque el ordenamiento italiano no prevé atenuantes de la antijuridicidad y, además, dispone de una rígida y paternalista interpretación sobre la propia integridad personal expresada en el artículo 5 del Código Civil, que prohíbe todo acto de disposición del propio cuerpo que pueda ocasionar un daño permanente a la integridad física (De Maglie, 2010, p. 185; Flavia Piqué, 2012, p. 2968).

Sin embargo, han existido intentos de justificación del factor cultural a través del apelo a causas de justificación, como lo fue en el conocido caso Bajrami (Cass. Sez. VI, sent. 24 noviembre de 1999), el cual corresponde a una situación de maltratamiento familiar. Los hechos indican que un inmigrante de origen albanés golpeaba y procuraba malos tratos tanto a su pareja como a los hijos, todos ellos también albaneses. Los hechos fueron denunciados, el imputado sometido a proceso y condenado. La defensa presentó apelación y conoció de esta la Corte de Casación.

Los argumentos presentados por el imputado señalaban que tanto la mujer como los hijos aceptaban voluntariamente los tratos recibidos y que, incluso, venían considerados como algo "natural" de acuerdo con un concepto de la convivencia familiar y de la patria potestad del jefe de familia "diverso" al existente en Italia. De acuerdo con lo anterior, se justificó que en Albania era frecuente que el jefe de familia dispusiera de una "potestad correctiva" sobre la mujer y los hijos que, en ocasiones, suponía el empleo de la violencia física. Con base en ello, el imputado consideraba estar obrando bajo una suerte de ius corrigendi que lo facultaba a comportarse en el modo señalado, por lo que en modo alguno podía reprochársele su conducta desplegada.

Frente a estos argumentos, la Casación señaló que, si bien es cierto que el imputado y las víctimas disponían de una idea sobre la potestad familiar diversa a la existente en Italia, y que eventualmente podría configurar no ya el ejercicio de un derecho sino más bien la hipótesis del consentimiento de la ofensa por parte de los ofendidos (artículo $50 \mathrm{CP}$ ), resultaba imposible de aplicar tal justificación a partir de la "divergencia insuperable" entre la conducta desplegada y los principios constitucionales de una "sociedad civilizada", frente a la cual no podían defenderse prácticas o costumbres "bárbaras y contrarias a los progresos obtenidos durante el transcurso de los siglos". Dicho lo cual, la Casación negó toda relevancia al factor cultural y confirmó la sentencia al imputado (Provera, 2018, p. 234; Monticelli, 2003, p. 576; Crocco, 2015, p. 122 y ss.). 
Esta sentencia merece algunos comentarios adicionales, ya que, de una parte, coincidimos en el resolutivo de la Casación, en tanto que prácticas culturales como las alegadas no pueden justificarse bajo un parámetro constitucional en el que se afirman derechos fundamentales básicos del individuo, como lo son la integridad y la dignidad personal. Sin embargo, los calificativos empleados por la Casación resultan enteramente fuera de lugar y, además, completamente reprobables porque vienen a afirmar la tantas veces criticada "voluntad misionaria" de ciertos operadores jurídicos, y de ciertos sistemas, con la que se pretende imponer determinados valores e interpretación del mundo a costa del desprecio e infravaloración de otros pueblos y culturas, sin tenerse mínimamente en cuenta que tales prácticas formaron, y en algunos casos siguen siendo parte, de la propia cultura asumida como superior.

A propósito, podemos recordar las hipótesis del "matrimonio reparador" en casos de abuso sexual o, incluso, a la "no punibilidad del marido" frente a la violencia carnal no consentida para con su esposa y, exactamente igual, las hipótesis de ius corrigendi reconocidas a los padres frente a los hijos e, incluso, frente a la propia esposa, todas ellas hipótesis que forman parte de un pasado no muy lejano en la historia del derecho italiano (Caterini, 2020, p. 127; Basile, 2007, p. 34 y ss.).

\section{III.3. Error y culpabilidad}

El ámbito de la culpabilidad ha sido señalado como, quizá, la categoría más adecuada para dar relevancia y reconocimiento al factor cultural (Fornasari, 2009, p. 177; Provera, 2018, p. 221; Masarone, 2004, p. 1246), toda vez que es en esta instancia en donde se realiza un examen particularizado sobre las características propias del agente que, en todo caso, sobre las que, en todo caso, podría valorarse su pertenencia cultural.

Concretamente, podría acudirse al instituto del error y a la ignorancia de la ley penal, siempre que tales situaciones no fueran directamente atribuibles al individuo y siempre que no hubiera tenido la oportunidad efectiva de liberarse de ellas, es decir, una situación de inevitabilidad. Al respecto, aunque no se refirió al caso particular de los delitos culturalmente motivados, la Corte Constitucional Italiana emitió el 30 de marzo de 1988 su sentencia No 364, la que ha sido considerada un "parteaguas" al determinar el significado y el alcance que debía darse a la ignorancia de la ley penal (Pulitanò, 1988, p. 686). En tal sentencia, la Corte señaló que podían tomarse en consideración "casos en los cuales el hecho haya sido cometido por un sujeto que, efectivamente, por ejemplo, haya llegado desde hace poco tiempo a nuestro país, aún dotado de conocimientos lingüísticos insuficientes o nulos, no autónomo del propio circulo étnico de pertenencia o, por análogas razones, que no conozca las disposiciones penales y no tenga aún instrumentos para conocerla o darse cuenta de su existencia" (citado en Masarone, 2004, p. 1246). 
Para algunos sujetos, de hecho, existe una imposibilidad objetiva de conocer las leyes penales. Piense en aquellas personas que se encuentran en situaciones de extrema vulnerabilidad, pobreza, discriminación y segregación social, obligadas a vivir exclusivamente en contacto con miembros de la comunidad de origen. A estos sujetos con "socialización insuficiente" no se les puede culpar en el mismo grado de desconocimiento de la ley. La mayoría de las veces, estas son reglas de conducta que parecerían evidentes a nuestros ojos occidentales, pero no así para las personas que pertenecen a culturas que son completamente diferentes a la nuestra y, precisamente, a partir de esto, la propia Corte Constitucional ha reconocido que las diversas categorías de delitos naturales y artificiales, en ciertos casos podrían no aplicarse, tal es, tratándose de los grupos en situación de vulnerabilidad a los que nos hemos referido.

Los delitos naturales, pueden ser entendidos como "aquellos cuyo contenido se revela a partir de reglas de conciencia moral y social" y, por tanto, la conciencia de la negligencia del hecho sería evidente; pensemos en el asesinato. Por el contrario, los delitos artificiales o delitos de mera creación legislativa serían aquellos cuyo "contenido de ilícito no se revela evidentemente, se articulan en conductas que no parten de la cultura o la moral", pensemos, por ejemplo, en algunos delitos propios omisivos (Maldonado Smith, 2020, p. 148).

Sin embargo, la sociedad multicultural de hoy revela que esta distinción no siempre es tan fácil. De hecho, esta distinción se basa "en el concepto de vida y experiencia del hombre occidental (...) es muy posible, es decir, que algunos delitos, que son naturales para nosotros, aparezcan en cambio como artificiales a sujetos pertenecientes a otros grupos étnicos, porque son conductas aceptadas y aprobadas por su cultura, aunque prohibidas por la ley de su estado" (De Maglie, 2010, p. 233).

El juicio extendido de reprobabilidad, por tanto, no se podía trasladar sobre todo hacía inmigrantes llegados muy recientemente $\mathrm{u}$ otros sujetos ya presentes en el territorio desde hace algún tiempo, pero portadores de diferentes culturas y sometidos a condiciones de extrema vulnerabilidad y exclusión. En armonía con el pensamiento de Zaffaroni, el sujeto que se encuentra en estado de vulnerabilidad no es culpable de ese estado (Zaffaroni, 2005, p. 622).

Por otro lado, en aquellos casos en los que el individuo sea consciente de la ilicitud de su conducta pero, no obstante, decida realizarla en razón de la enorme carga cultural que sobre él recae y que, evidenciaría una colisión entre sistemas normativos (el jurídico italiano y el cultural del individuo) habría que valorar caso por caso la presión que sobre el individuo puede ejercer ese cúmulo de elementos para, eventualmente, argumentar una situación de inexigibilidad de una conducta diversa (Masarone, 2014, p. 1248; Basile, 2007, p. 417; Flavia Piqué, 2012, p. 2967). 
Un caso que presentamos en relación con la figura del error tiene que ver con la "apreciación diversa" que en otras culturas puede existir respecto de creencias como la sexualidad y el papel de la mujer. Los hechos se refieren a una pareja de jóvenes inmigrantes marroquíes que, una vez en Italia (2007), formalizan el matrimonio concertado por sus padres. Hecho lo anterior, la pareja da pauta a iniciar la convivencia, en la que el marido, alegando un derecho de su cultura, obliga a la mujer a tener relaciones sexuales reiteradas. La mujer escapa y denuncia a su esposo quien es condenado en primera instancia. Se presenta recurso de apelación y conoce de este la Casación (sent. 26 junio 2007, № 34909).

La defensa señaló que, en el caso particular, se verificaba una situación de error invencible, toda vez que en Marruecos dicha conducta no era sancionada y que, adicionalmente, formaba parte de una tradición ampliamente difusa en la cultura marroquí. En efecto, en tal cultura, el hombre casado puede exigir y disponer libremente de relaciones sexuales con su mujer, independientemente de la voluntad de esta.

La Casación resolvió que resultaba completamente irrelevante el que la conducta alegada fuese permitida por el derecho o la costumbre marroquí pues afectaba derechos fundamentales del individuo, como lo es la libre autodeterminación sexual, frente a la cual la cultura de ningún modo podía sobreponerse. Además, no era dable sostener una hipótesis de error invencible pues, en términos de la sentencia 364 de 1988 (sobre la ignorancia inevitable de la ley penal), el individuo tenía un deber de informarse respecto de la ilegalidad de la conducta desplegada, situación que, en los hechos, omitió realizar.

Pese a todo lo anterior, la Casación admitió que el factor cultural incidió en la conducta desplegada, más no la determinó completamente porque el imputado tuvo la posibilidad de informarse y de evitarla. En consecuencia, se determinó la responsabilidad penal del individuo, pero, al mismo tiempo, se consideró aplicable una atenuante con base en el factor cultural (Basile, 2017 p. 134; Gentile, 2009, p. 421).

\section{Consideraciones y reflexiones}

Sin lugar a dudas, la muestra de casos presentada en este trabajo de ningún modo pretende ser representativa de la situación general existente en Italia o en Argentina; se requieren muchos más datos y de una investigación mixta que conjugue lo cualitativo y cuantitativo para poder derivar conclusiones generales aplicables a la realidad de los países estudiados. Este trabajo no ha pretendido tal aspiración sino más bien dar una pequeña muestra de cómo el factor cultural, más allá de las naturales diferencias contextuales, actualmente viene considerado 
por la jurisprudencia al interior de las categorías tradicionales de la dogmática penal y cómo, en muchos casos, viene asumida una posición "abierta" frente a la pluralidad.

De este modo, los casos estudiados, y solo estos, nos permiten identificar algunas coincidencias y divergencias. En el primer plano, y como adelantamos, el factor cultural viene valorado independientemente del tipo de sociedad multicultural (multinacional o multiétnica), aunque, como también se ha visto, existe una especie de preferencia o selectividad frente a especificidades culturales que son más valoradas que otras (Caterini, 2020 p. 121 y ss.; Crocco, 2015, p. 138; Fantauzzi, 2011 p. 227). Del mismo modo, también se ha visto que el factor cultural se toma en consideración a partir de su encuadramiento en alguna de las hipótesis que permitirían la ausencia de responsabilidad penal, ya sea a través de una ausencia de tipicidad, una causa de justificación o una eximente de la culpabilidad.

El caso italiano permite una utilización plural de las categorías tradicionales de la dogmática, aunque se aprecia una mayor preferencia por la culpabilidad (Flavia Piqué, 2012, p. 2968). En el ámbito de la tipicidad, se ha dado relevancia al factor cultural ya sea mediante argumentaciones que permiten determinar la ausencia de dolo, un motivo justificado o una interpretación abierta de los elementos normativos del tipo penal.

Al interior de la culpabilidad, se da prevalencia, sobre todo, a la figura del error, pero bajo especiales circunstancias que han sido delineadas a partir de la Sentencia 364 de 1988. Del mismo modo, la inexigibilidad de una conducta diversa también ha sido señalada como una posible vía de análisis. La antijuridicidad, sin embargo, es poco utilizada al resultar complejo justificar la afectación de un bien jurídico fundamental a partir de una conducta culturalmente motivada y, al mismo tiempo, al disponer el ordenamiento italiano de cláusulas como el artículo 5 del Código Civil.

La situación argentina resulta diversa pues, en los casos presentados, hemos visto que suele darse especial preponderancia a emplear la categoría dogmática de la culpabilidad, a partir del error de prohibición y, en especial, mediante la utilización de la propuesta de Zaffaroni en torno a un error de prohibición culturalmente condicionado. La figura de la tipicidad y de la antijuridicidad, aunque en menor medida, vienen igualmente empleadas.

Otro aspecto interesante de nuestro trabajo ha dado cuenta de los retos y dificultades aún presentes cuando se interpreta la multiculturalidad. En Italia parece ser que no existe una tendencia precisa que permita calificar la posición asumida como multicultural o asimilacionista. Tanto las normas como su interpretación por vía jurisprudencial manifiestan ambigüedades que en algunos casos se 
pronuncian por un claro reconocimiento y valoración de las diferencias culturales, pero, en otros casos, se erigen con perfil hiper punitivo y criminalizador, particularmente cuando se trata de migrantes extracomunitarios.

Argentina, por su parte, parece haber asumido una clara posición multicultural, pero en la que prevalecen dificultades, especialmente cuando se trata de armonizar el derecho a la identidad cultural con otros derechos fundamentales. La situación no ha sido sencilla y no ha estado exenta de críticas, en especial de parte de otros colectivos en situación de desigualdad y marginación social, frente a los cuales parecería que la cultura viene privilegiada sacrificando otros intereses de igual consideración.

Nadie dijo que asumirse como un Estado multicultural fuera sencillo; con seguridad, los retos y dificultades a los que tendrán que hacer frente estos Estados serán mucho mayores a los asumidos por un Estado que defiende la homologación; sin embargo, de nuestra parte consideramos que el más elemental sentido de la justicia implica repensar nuestras instituciones y la forma en cómo hemos construido nuestros Estados. Aristóteles, en La política, señalaba que un banquete es más rico y variado si cada uno de los comensales lleva consigo una comida y mucho más pobre si es organizado por solo uno de ellos. Somos partidarios de que, a pesar de las dificultades, nuestros Estados, la democracia, los derechos fundamentales y las instituciones en las que creemos, más allá de verse en peligro ante la diversidad cultural, pueden aprender de ella y enriquecernos mutuamente. En un mundo enteramente multicultural, no existe mayor peligro que la cerrazón, el miedo o el odio hacía la entera pluralidad que nos rodea.

\section{Bibliografia}

Abduca, R. y Metaal, P. (2013). Hacia un mercado legal para la coca: el caso del coqueo argentino. Reforma legislativa en materia de drogas, № 23. Amsterdam: Transnational institute.

Amaya, S. (2015). Neuquén: un jurado intercultural absolvió a la dirigente mapuche Relmu Ñamku. Nota de 4 de noviembre. Recuperado de https://www.lanacion.com.ar/seguridad/neuquen-un-jurado-intercultural-absolvio-a-la-mujermapuche-relmu-namku-nid1842662/

Basile, F. (2007). Società multiculturali, immigrazione e reati culturalmente motivati (comprese le mutilazioni genitali femminili). Stato, chiese e pluralismo confessionale. Milano: Università degli studi di Milano.

Basile, F. (2013). Assolti in appello i primi (e finora) unici imputati per il reato di cui all'art. 583 bis cp: un commento alla sentenza della Corte d'appello di Venezia 
del 23 novembre 2012. Diritto, immigrazione e cittadinanza, № 2 (pp. 61-81). Firenze: Franco Angeli Editore.

Basile, F. (2013). Il reato di "pratiche di mutilazione degli organi genitali femminili" alla prova della giurisprudenza: un commento alla prima (e finora unica) applicazione giurisprudenziale dell'art. 583-bis c.p. Stato, chiese e pluralismo confessionale. Milano: Università degli studi di Milano.

Basile, F. (2017). I reati cd. "culturalmente motivati" commessi dagli immigrati. Questione giustizia, No 1 (pp. 126-135). Roma: Associazione Magistratura Democratica.

Benitez, N. (2016). El error de prohibición culturalmente condicionado. Análisis dogmático, jurisprudencial y normativo. Revista Virtual Intercambios, № 17 (pp. 1-28). La Plata: Universidad Nacional de la Plata.

Bernardi, A. (2006). Modelli penali e società multiculturale. Torino: Giappichelli Editore.

Bidart Campos, G. (1994). Tratado Elemental de Derecho Constitucional Argentino, T. VI. Buenos Aires: Ediar.

Bricola F. (1960). Dolus in re ipsa. Osservazioni in tema di oggetto e di accertamento del dolo. Milano: Giuffrè.

Broeck, J. V. (2001). Cultural defense and culturally motived crimes (cultural offences). European Journal of Crime, Criminal Law and Criminal Justice, No 9 (pp. 1-32). Amsterdam: Martinus Nijhoff Publishers.

Bouchard, M. (2000). Dalla famiglia tradizionale a quella multietnica e multiculturale: maltrattamenti e infanzia abusata in dimensione domestica. Diritto, Immigrazione e Cittadinanza, No 1 (pp. 19-42). Firenze: Franco Angeli Editore.

Caputo, A. (2009). Il reato di immigrazione clandestina. Criminalia, Annuario di scienze penalistiche (pp. 387-404). Pisa: ETS Editore.

Catenacci, M. (2006). I reati di pericolo presunto fra diritto e processo penale. En E. Dolcini y C.E. Paliero (coordinadores). Studi in onore di Giorgio Marinucci. vol. II (pp. 1415-1492). Milano: Giuffrè.

Caterini, M. (2011). Lo strabismo deeticizzante del legislatore penale economico: è forse vero che l'etica vale solo per i poveri e gli stupidi? En C. Martínez Sicluna y Sepúlveda, L'etica nel mercato. Milano: CEDAM. 
Caterini, M. (2015). Il diritto penale del nemico «presunto». Politica del diritto, V. XLVI, No 4. Bologna: Il Mulino Editore.

Caterini, M. (2017). Effettività e tecniche di tutela nel diritto penale dell'ambiente. Contributo ad una lettura costituzionale orientata. Napoli: Edizioni Scientifiche Italiane.

Caterini, M. (2020). "Reati cultural": politiche criminali e prassi applicative tra Italia e Germania. Politica del diritto, V. LI, No 1 (pp. 117-138). Bologna: Il Mulino Editore.

Cavaliere, A. (2017). Italia, Derecho penal máximo y diversión discrecional, Una hipótesis sobre neoliberalismo y política criminal, desde una perspectiva italiana. Revista de Derecho Penal y Criminología. No 11 (pp. 155-168). Buenos Aires: La Ley.

Cerezo Mir, J. (2006). Temas fundamentales del Derecho Penal, Tomo I. Santa Fe: Rubinzal-Culzoni.

Cerezo Mir, J. (2002). Los delitos de peligro abstracto en el ámbito del derecho penal del riesgo. Revista de derecho penal y criminología, No 10 (pp. 47-72). Madrid: UNED.

Caesano, J. D. (2009). Diversidad Cultural y Teoría del error. Horizontes y convergencias. Lecturas históricas y Antropológicas sobre el Derecho (pp. 1-32). Córdoba: Horizontesyc.

Comanducci, P. (1995). Derechos humanos y minorías: un acercamiento analítico neoilustrado. Isonomía: Revista de Teoría y Filosofía del Derecho, № 3. (pp. 21-42). Ciudad de México: ITAM.

Crocco, G. (2015). Sistema penale e dinamiche interculturali ed interreligiose. Diritto e religioni, No 1 (pp. 108-155). Cosenza-Napoli: Luigi Pellegrini editore.

De Maglie, C. (2010). I reati culturalmente motivati, Ideologie e modelli penali. Pisa: ETS Editore.

Donini, M. (1991). Illecito e colpevolezza nell'imputazione del reato. Milano: Giuffrè.

Donini, M. (2008). Danno e offesa nella c.d. tutela penale dei sentimenti. Rivista italiana di diritto e procedura penale, V.51, No 4 (pp. 1546-1593). Milano: Giuffrè Editore. 
Fantauzzi, A. (2011). Mutilazioni Genitali Femminili: quando l'etica s'incontra/ scontra con la cultura e la religione. En S. Scotti y M. Zarate (coords.), Etica pubblica e religione (pp. 221-228). Firenze: Pagliai Editore.

Fornasari, G. (2008). Mutilazione femminili e multiculturalismo: premesse per un discorso giuspenalistico. En A. Bernardi, B. Pastore y A. Pugiotto (coords.), Legalité penale e crisi del diritto, oggi. Un percorso interdisciplinare (pp. 179-202). Milano: Giuffrè.

Fornasari, G. (2009). Le categorie dogmatiche del diritto penale davanti alla sfida del multiculturalismo. En: W. Hassemer, E. Kempf, S. Moccia (cords.). In dubio pro libertate. Festschrift für Klaus Volk zum 65. Geburtstag (pp. 177-192). Múnich: Beck C.H.

Gatta, G. L. (2015). La criminalizzazione della clandestinità fra scelte nazionali e contesto europeo. Rivista italiana di diritto e procedura penale, V. 58, No 1 (pp. 188-198). Milano: Giuffrè Editore.

Gentile, A. (2009). Violenza sessuale in matrimonio retto da diritto straniero: il prudente approccio della Cassazione ai c.d. "reati culturali". Rivista italiana di diritto e procedura penale (pp. 421-439). Milano: Giuffrè Editore.

Grandi, C. (2011). A proposito di reati culturalmente motivati. Diritto Penale Contemporaneo (pp. 1-26). Milano: Associazione Progetto giustizia penale.

Grasso, G. (1986). L'anticipazione della tutela penale: i reati di pericolo e i reati di attentato. Rivista italiana di diritto processuale penale (pp. 689-728). Milano: Giuffrè Editore.

Grisetti, R. A. y Kamada, L. (2013). Error de prohibición. Los derechos humanos como límite natural a su respeto irrestricto. La Ley, № 23 (pp. 9-12). Buenos Aires: La Ley.

Grosso, E. (2006). Multiculturalismo e diritti fondamentali nella Costituzione italiana. En A. Bernardi (coord.), Multiculturalismo, diritti umani, pena (pp. 109-136). Milano: Giuffrè Editore.

Jiménez Fortea, F. El proceso penal de los pueblos indígenas de Latinoamérica: Una visión desde Europa. Otras Justicias. Sistemas judiciales. Una perspectiva integral sobre la administración de justicia, № 12 (pp. 16-41). Buenos Aires: CEJA Editore.

Kymlicka, W. (1999). La cittadinanza multiculturale, trad. G. Gasperoni. Bologna: Il Mulino Editore. 
ARGENTINA E ITALIA ANTE LA DIVERSIDAD CULTURAL: VALORACIÓN EN SEDE PENAL DEL FACTOR CULTURALMENTE RELEVANTE - MARIO CATERINI Y

Longobardo, C. (2001). Le mutilazioni genitali femminili. En A. Cilardo (coord.), La tutela dei minori di cultura islamica nell'area mediterranea (pp. 55-85). Napoli: ESI Editore.

Maldonado Smith, M.E. (2020). Multiculturalismo, principi e diritto penale. Una comparazione tra gli ordinamenti italiano e messicano. Tesis Doctoral. Napoli: Università degli studi di Napoli, Federico II.

Manna, A. (2011). Il diritto penale dell'immigrazione clandestina, tra simbolismo penale e colpa d'autore. Cassazione Penale, V. 51, No 2 (pp. 446-457). Milano: Giuffrè Editore.

Marinucci, G., y E. Dolcini. (2015). Manuale di diritto penale. Parte generale. $5^{\circ}$ ed. Milano: Giuffrè Editore.

Masarone, V. (2014). L'incidenza del fattore culturale sul sistema penale tra scelte politico-criminali ed implicazioni dommatiche. Diritto penale e processo, No 10 (pp. 1237-1250). Milano: IPSOA.

Mir Puig, S. (2016). Derecho penal. Parte general, 10 ed. Barcelona: Reppertor Editore.

Moccia, S. (2008). Leggi speciali. Immigrazione criminalizzata. Il Manifesto, 23 de mayo. Roma: Società Cooperativa Editrice il Nuovo Manifesto.

Monticelli, L. (2003). Le cultural defences (esimenti culturali) e i reati culturalmente orientati. Possibili divergenze tra pluralismo culturale e sistema penale. Indice penale, v. 6, № 2 (pp. 535-586). Padova: CEDAM.

Olguín Ríos, M. J. (2018). Problemas de tipicidad por factores culturales. Revista de Derecho Penal y Criminología, № 7. Buenos Aires: La Ley.

Piqué, F. (2012). La subcultura del marito non elide l'elemento soggettivo del reato di maltrattamenti ne esclude l'imputabilità del reo. Cassazione penale, V. 52, No 9 (pp. 2962-2976). Milano: Giuffrè Editore.

Pistorelli, L. (2008). Commento alle disposizioni per il controllo delle armi. En A. Crespi, G. Gabri y G. Zuccalà (coords.), Commentario Breve al Codice Penale. Padova: CEDAM.

Pozze, E. (2017). Derechos de las mujeres y derechos culturales de las minorías étnicas. Revista de Estudios de la Mujer, № 21 (pp. 129-144). Santa Rosa: Universidad Nacional de la Pampa. 
Provera, A. (2010). Il giustificato motivo: la fede religiosa come limite intrinseco della tipicità. Rivista italiana di diritto e procedura penale (pp. 964-979). Milano: Giuffrè Editore.

Provera, A. (2018). Tra frontiere e confini. Il diritto penale dell'età multiculturale. Napoli: Jovene Editore.

Pulitanò, D. (1988). Una sentenza storica che restaura il principio di colpevolezza. Rivista italiana di diritto e procedura penale (pp. 686-730). Milano: Giuffrè Editore.

Rabbi Baldi, R. (2011). Universalismo y multiculturalismo. Un análisis filosófico-jurídico a la luz de la jurisprudencia sobre pueblos originarios en la jurisdicción de Salta. Academia Nacional de Derecho de Córdoba (pp. 1-20). Córdoba: ANDC.

Ramírez, S. (2006). La guerra silenciosa. Despojo y resistencia de los pueblos indígenas. Buenos Aires: Capital Intelectual.

Ramírez, S. (2007). Justicia Penal y Pueblos indígenas: una agenda pendiente. Sistemas Judiciales. Una perspectiva integral sobre la administración de justicia, No 12 (pp. 6-15). Buenos Aires: CEJA Editore.

Restón M. I. (2017). Delito y diversidad cultural. Una propuesta de solución para los delitos cometidos desde una motivación cultural diversa. Tesis doctoral. Barcelona: Universitat Abat Oliba CEU.

Rocella, A. (2000). Macellazione rituale e diritto islamico. En S. Ferrari (coord.), Musulmani in Italia. La condizione giuridica delle comunità islamiche (pp. 201-221). Bologna: Il Mulino Editore.

Santamaria, D. (1961). Interpretazione e dommatica nella dottrina del dolo. Napoli: Jovene Editore.

Scafi, P. (2010). La modifica di singole norme incriminatrici e l'introduzione di nuove fattispecie di reato. En F. Ramacci y G. Spangher (coords.), Il sistema della sicurezza pubblica (pp. 619-643). Milano: Giuffrè Editore.

Scalia, M. (2009). Le modifiche in materia di tutela dei minori. Diritto Penale e Processo, No 10 (pp. 1207-1222). Milano: IPSOA.

Scoletta, M. (2009). Nuovo delitto di minori nell'accattonaggio; Sequestro di persona: nuove circostanze aggravanti e attenuanti. En AA.VV, Sistema penale e sicurezza pubblica: le riforme del 2009 (pp. 113-132). Milano: Giuffrè Editore. 
Stornelli, M. (2019). Diversidad cultural y derecho penal. Delitos culturalmente motivados. Revista Jurídica AMFJN. № 7 (pp. 19-32). Buenos Aires: Asociación de Magistrados y Funcionarios de la Justicia Nacional.

Tarducci, M. (2013). Abusos, mentiras y videos. A propósito de la niña wichi. Boletín de Antropología y Educación, No 5 (pp. 6-13). Buenos Aires: Universidad de Buenos Aires.

Valenzuela Reyes, M. (2003). Derechos de los pueblos indígenas en el contexto internacional, especialmente en lo relativo a los aspectos penales. Revista de Estudios Criminológicos y penitenciarios, № 6 (p. 9). Santiago de Chile: Ministerio de Justicia.

Van Cott, D. L. (2000). The friendly liquidation of the past: the politics of diversity in Latin America. Pittsburgh: University of Pittsburgh Press.

Vázquez Neira, L. F. (2010). La diversidad cultural en la teoría del delito. Revista Ibero-Americana de Ciências Penais, № 19 (pp. 9-38). Porto Alegre: FMP Editore.

Villalba, S. M. (2014). Reclamo indígena de participación en gestión de Áreas Naturales Protegidas. Casos en Argentina y en Paraguay. Cuadernos Deusto de Derechos Humanos, No 74 (pp. 153-170). Bilbao: Universidad de Deusto.

Villavicencio Terreros, F. (2011). Tratamiento Penal de la Diversidad Cultural por la Justicia Estatal del Perú. Dans Revue Internationale de Droit Pênale, V. 82 (pp. 559-573). Paris: Erés editor.

Zaffaroni, E. R. (2005). Tratado de Derecho Penal, Parte General. Tomo IV, $2^{\mathrm{a}}$ ed. Buenos Aires: Ediar.

\section{Jurisprudencia argentina}

Consultable en el Sistema Argentino de Información Jurídica (SAIJ): http:// www.saij.gob.ar/

Cámara Federal de Resistencia, "Santillán, Agustín y otros s/interrupción de los medios de comunicación y transporte por tierra, art. 194 c. p", 3 de agosto de 2012.

Cámara Nacional de Apelaciones en lo Criminal y Correccional de la Ciudad de Bs. As., "Su Shao Mei y otra", 18 de marzo de 2002.

Cámara Nacional de Apelaciones en lo Criminal y Correccional, Sala III. 16 noviembre 1979. 
Corte de Justicia de Salta, “C/C Ruíz, José Fabián -Recurso de Casación”, 29 de septiembre de 2006.

Juzgado Federal de apelación de Formosa, "Astorga Ariel y otros s/ inf. Art. 194 C.P.A.", 6 de diciembre de 2012.

Juzgado Nacional en lo criminal, "Prieto Huanca, Timoteo y otra", 30 de marzo de 1979.

Tribunal de Impugnación de Neuquén, “Campo, Juan Albino y otros s/usurpación (art. 181)", 26 de abril de 2019.

Tribunal Oral en lo Criminal Federal n. 1 de la Plata, "Hoyos Noguera, Juan Pablo y otros s/inf. Arts. 119 inc. F y 145 ter del c.p.", 4 de diciembre de 2013.

Tribunal Superior de Justicia de Neuquén; “Puel s/daño", 12 de marzo de 1999.

\section{Jurisprudencia italiana}

Cass. Sez. 26 junio de 2007, n. 34909. Publicada en: Rivista italiana di diritto e procedura penale, v. 55, 2008 (pp. 421-439), con nota de Gentile, A. Milano: Giuffrè.

Cass. Sez. VI, 24 noviembre de 1999, n. 3398 (Bajrami). Publicada en: Giustizia penale, 2000. Roma: Soc. edit. La Giustizia Penale.

Corte Constitucional Italiana, 30 de marzo de 1988, n. 364. Publicada en: Foro italiano. 1988, I, 1385, con nota di G. Fiandaca. Roma: Società editrice Il Foro Italiano.

Tribunal de Apelación de Venecia, 23 de noviembre de 2012, n. 15485. En: Basile, F. Assolti in appello i primi (e finora) unici imputati per il reato di cui all'art. 583 bis cp: un commento alla sentenza della Corte d'appello di Venezia del 23 novembre 2012. Diritto, immigrazione e cittadinanza, 2013, n. 2 (pp. 61-81). Firenze: Franco Angeli Editore.

Tribunal de Cremona en 2009, 19 de febrero de 2009, n. 15. Publicada en: Il Corriere del Merito. n. 4, 2009 (pp. 395-405). Bologna: IPSOA Editore.

Tribunal de Cremona, 28 de noviembre de 2008, n. 78. Publicada en: Il Corriere del Merito. n. 3, 2009 (pp. 295-302). Bologna: IPSOA Editore.

Tribunal de Menores de Piemonte y Valle d'Aosta, 17 julio 1997, n. 247. Publicada en Minotigiustizia, n. 3, 1999. Firenze: Franco Angeli Editore. 
Tribunal de Verona, 14 de abril de 2010, n. 979. Publicada en: Diritto, immigrazione e cittadinanza. N. 3. 2010 (pp. 209-244). Firenze: Franco Angeli Editore.

Fecha de recepción: 03-03-2021

Fecha de aceptación: 29-09-2021 
